\title{
Calcific myonecrosis following snakebite
}

\author{
N Ferreira BSc, MBChB, FC Orth(SA), MMed(Orth), PhD \\ Department of Orthopaedic Surgery, Tygerberg Hospital, Stellenbosch University, Cape Town, South Africa \\ LC Marais MBChB, FCS Orth(SA), MMed(Ortho), PhD \\ Department of Orthopaedic Surgery, Grey's Hospital, Nelson R Mandela School of Medicine, \\ University of KwaZulu-Natal, Pietermaritzburg, South Africa
}

\author{
Corresponding author: \\ Dr Nando Ferreira \\ Department of Orthopaedic Surgery \\ Tygerberg Hospital \\ Stellenbosch University \\ 7505 Cape Town \\ South Africa \\ Tel: +27 219384911 \\ Email: nferreira@sun.ac.za
}

\begin{abstract}
Calcific myonecrosis is a rare condition and is believed to be a late sequela of untreated compartment syndrome. Patients usually present with a progressively enlarging mass, years after the initial injury, that can be misdiagnosed as a soft tissue sarcoma. Calcific myonecrosis following snakebite is extremely rare. The anterior compartment of the leg is most frequently involved and appears to be especially vulnerable to developing this complication. Conservative management should be considered in asymptomatic patients but spontaneous soft tissue breakdown with sinus formation may develop and prolonged surveillance is advised. We report two similar cases of calcific myonecrosis of the anterior compartment of the lower leg that developed decades following snakebite.
\end{abstract}

Key words: calcific myonecrosis, compartment syndrome, soft tissue calcification, snakebite

http:/ / dx.doi.org/10.17159/2309-8309/2017/v16n1a3

\section{Introduction}

Calcific myonecrosis is a rare condition and less than 50 cases have been reported in the English literature. It was first described by Gallie and Thompson in 1960 as a late sequela of compartment syndrome. ${ }^{1}$ Although a hypothesis for the development of this complication was proposed by Janzen et al. in 1993 and O'Keefe et al. in 1995, the exact physiological mechanism is not fully understood. ${ }^{2,3}$

The condition is characterised by muscle necrosis of an entire osteofacial compartment with central liquefaction and peripheral calcification. The clinical and radiographic findings can be misdiagnosed as a soft tissue sarcoma. ${ }^{4-6}$ Differential diagnosis includes synovial sarcoma and soft tissue osteosarcoma as well as benign conditions like myositis ossificans, dermatomyositis, tumoral calcinosis and calcific tenosynovitis (Table I). ${ }^{5}$

We report two similar cases of calcific myonecrosis of the anterior compartment of the lower leg following snakebites and review the available literature on this rare condition.
Table I: Differential diagnosis of calcified soft tissue lesions

\section{Malignant conditions}

Benign conditions

\begin{tabular}{|l|c|}
\hline Synovial sarcoma & Heterotypic ossification/myositisossificans \\
\hline $\begin{array}{l}\text { Epithelioid sarcoma } \\
\text { Soft tissue osteosarcoma }\end{array}$ & Dystrophic soft tissue calcification \\
\hline $\begin{array}{l}\text { Soft tissue mesenchymal } \\
\text { ondrosarcoma }\end{array}$ & Dermatomyositis/polymyositis \\
& Tumoral calcinosis \\
& Diabetic myonecrosis \\
& Calcific tenosynovitis \\
\hline
\end{tabular}

\section{Case report}

Two similar cases were managed at our unit during the same year. These cases involved female patients aged 62 and 81 years respectively, who both reported a painless, progressively enlarging mass in the anterolateral aspect of 
the left and right lower leg respectively. In both cases the mass was initially noted approximately one year prior to presentation. Both patients reported a snakebite to the lower leg decades earlier. The first patient sustained a snakebite at the age of 13 years (49 years earlier) while the second patient was 16 years old (65 years earlier) at the time of the injury.

Clinical examination revealed a large, painless, fluctuant mass located in the anterior compartment of the leg of both cases. One patient presented with two sinuses that developed spontaneously and drained white 'toothpaste-like' liquid. Radiographs confirmed a calcified soft tissue mass in the anterior compartment of the leg in both patients. The masses had a fusiform appearance with linear calcifications and well defined borders. (Figures $1 a$ and $1 b$ ) In both cases the tibia and fibula were uninvolved. Magnetic resonance imaging (MRI) demonstrated T1 isointense and T2 hypointense fusiform lesions along the tibialis anterior muscles with a thin rim of low signal capsule and no contrast enhancement (Figure 2).

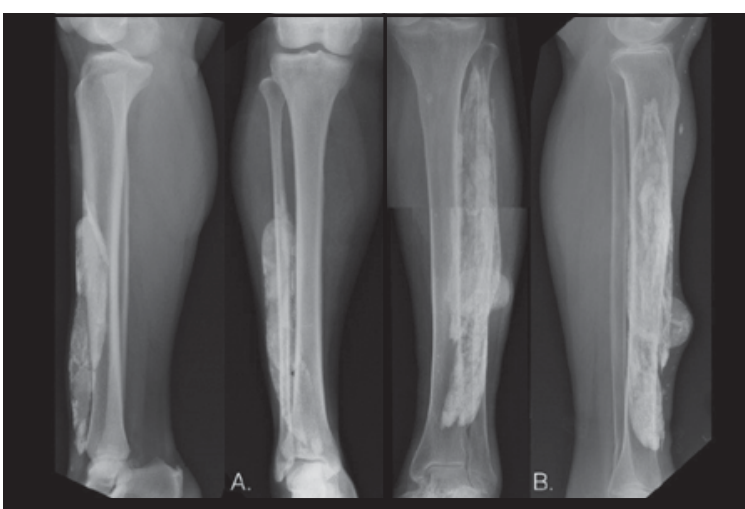

Figure 1. Antero-posterior and lateral X-ray images of both patients. Fusiform calcified lesions can be seen in the anterior compartment.

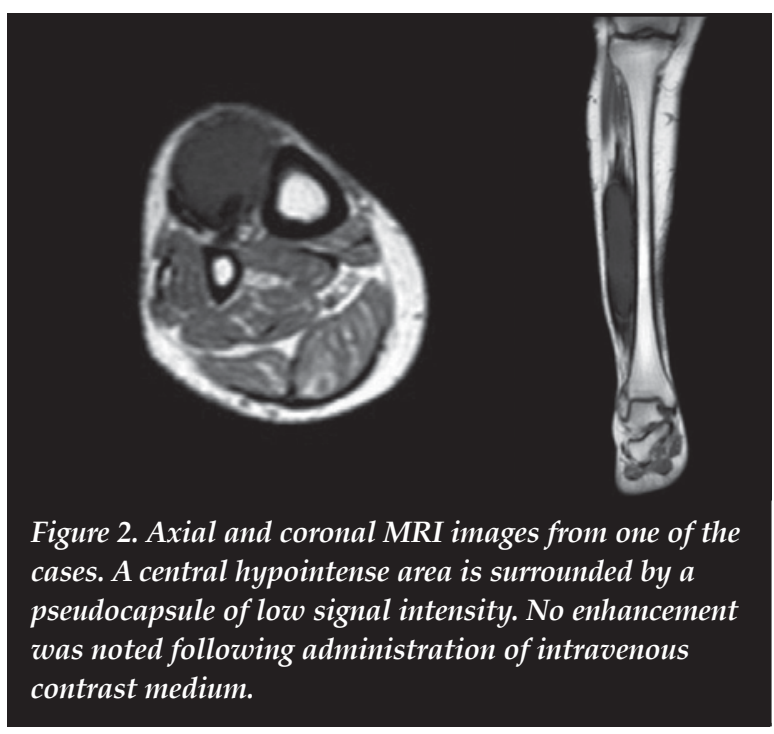

Management consisted of surgical debridement, prolonged suction drainage and a short course of prophylactic antibiotics in both cases. Macroscopic examination of the specimens revealed elongated shards of debris that corresponded to the linear calcifications identified in the radiographs (Figure 3). Histological examination showed lesions composed of calcific debris surrounded by fibroconnective tissue septae, and confirmed the diagnosis of tumoral calcinosis in both cases. Both patients were followed up for six months after surgery. While one patient had complete healing of the surgical incisions with no reaccumulation or septic complications, the patient that presented with draining sinuses had persistent drainage from these sinuses for two months following the surgery.

\section{Discussion}

Calcific myonecrosis is a rare condition and its pathophysiology is not well understood. The anterior compartment of the leg is most frequently affected, but other anatomical locations including the upper limbs have also been reported..$^{5-7}$ It usually follows several years after trauma and is probably related to an untreated compartment syndrome. Compartment syndrome usually results from trauma but has been reported following snakebites. ${ }^{7-15}$ These bites are usually from snakes that produce cytotoxic venom and most reports implicate snakes from the Viperidae family. Snake venom contains at least 26 different types of enzymes; 12 of these enzymes are common in all venoms, and the rest occur separately in certain species. ${ }^{16} \mathrm{Up}$ to $80-90 \%$ of Viperidae venom consists of enzymes that possess very strong proteolytic activity, while that of Elapidae, with the exception of the $\mathrm{m}^{\prime}$ Fezi or Mozambique spitting cobra (Naja mossambica), have very weak proteolytic action. ${ }^{17}$

Vipers have long, hinged fangs that permit deep envenomation of proteases, peptid hyaluronidases and phospholipases that cause vascular endothelial damage with resultant oedema and local tissue necrosis. ${ }^{7-9}$

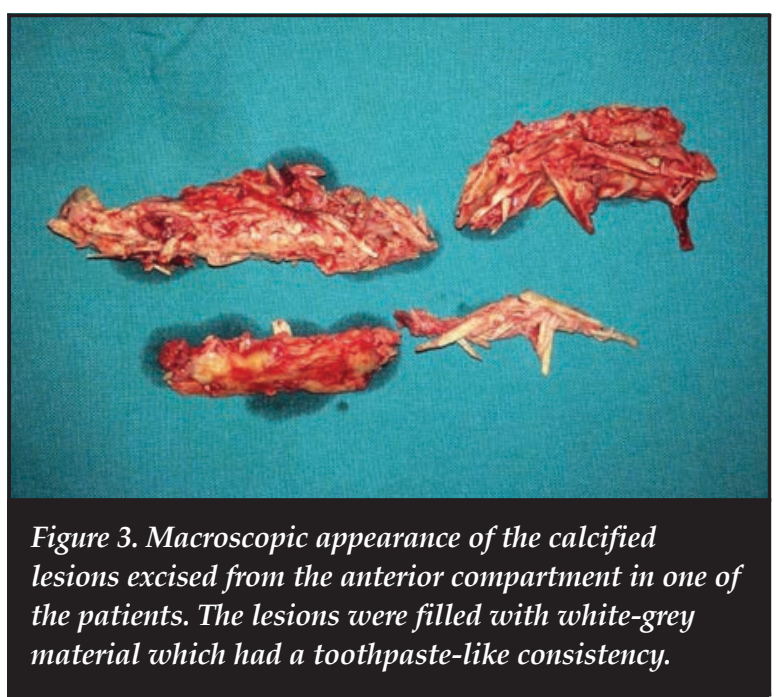


Only two reports of calcific myonecrosis following snakebites have been reported in the English literature and these cases are almost identical to the cases presented here. Yuenyongviwat et al. reported a case of a 66-year-old Thai woman who presented with calcific myonecrosis 52 years after being bitten by a Malayan pit viper (Calloselasma rhodostoma). ${ }^{18}$

The anterior compartment of the leg was affected and after a four-year period of conservative management, soft tissue breakdown necessitated surgical intervention in the form of mass resection and primary closure with vacuum drainage. Chun et al. also reported a case of calcific myonecrosis following a snakebite. Their case presented 44 years after being bitten, again involved the anterior compartment of the leg and was treated by mass resection. ${ }^{19}$

Although neither of our patients could recall the species of snake, a member of the Viperidae family was probably involved. Three viper species are frequently encountered in KwaZulu-Natal, including the puff adder (Bitis arietans), berg adder (Bitis atropos) and night adder (Causus rhombeatus). ${ }^{15}$

The puff adder specifically, is one of the most common venomous snakes in South Africa and is responsible for more fatal bites than any other snake. If not fatal, puff adder bites frequently result in extensive necrosis that may require amputation of the affected limb. ${ }^{20}$

A bite from one of these snakes is consistent with previous reports of compartment syndrome $e^{7,13,14,21}$ and calcific myonecrosis ${ }^{18,19}$ following viper bites. Interestingly, venom from the saw-scaled viper (which contains ecarin that activates prothrombin) has also been associated with renal cortical necrosis followed by calcification. ${ }^{16}$

Acute anterior compartment syndrome involves the isolated anterior compartment of the lower leg and usually follows trauma. ${ }^{22}$

Wood et al. reported that approximately $9 \%$ of patients with rapid progressive swelling (RPS) after serious snakebites develop compartment syndrome..$^{23}$

In the acute setting, management involves release of this compartment through a fasciotomy. Compartment syndrome as a result of snakebite frequently involves the anterior compartment in isolation and may be the result of envenomation of this compartment and the specific anatomical characteristics of the anterior compartment of the lower leg. The sequelae of untreated compartment syndrome include rhabdomyolysis, permanent nerve damage, contracture and loss of function, infection and even amputation. Calcific myonecrosis is believed to be a rare complication of untreated compartment syndrome and follows several years to decades after the trauma.

Conservative management of calcific myonecrosis is advised in asymptomatic patients. Some authors even propose that calcific myonecrosis be considered as 'don't-touch' lesions due to the high risk of infection following surgical intervention. ${ }^{24-27}$ A conservative approach does not, however, preclude infective complications.
Affected patients may present with soft tissue breakdown as the mass enlarges and de novo infection has also been reported. ${ }^{5}$ Spontaneous soft tissue breakdown with sinus formation was seen in one of our cases and in the case reported by Yuenyongviwat et al. ${ }^{18}$

Patients with calcific myonecrosis should be followed closely so that early intervention can be initiated once soft tissue breakdown occurs.

The theory that calcific myonecrosis develops after compartment syndrome suggests that a treatable cause for this complication exists. Patients who present with snakebites to the lower limb should be carefully evaluated for compartment syndrome and the appropriate treatment instituted.

\section{Conclusion}

Calcific myonecrosis is a rare complication following snakebites. The anterior compartment of the leg is most frequently involved and appears especially vulnerable to developing this complication. Conservative management should be considered in asymptomatic patients but spontaneous soft tissue breakdown with sinus formation may develop, and prolonged surveillance is advised.

\section{Compliance with Ethics Guidelines}

Written consent was obtained from both patients for publication of this report and any accompanying images. A copy of the written consent is available for review by the Editor-in-Chief of this journal.

The content of this article in the sole work of the authors. No benefits of any form have been received or will be received from a commercial party related directly or indirectly to the subject of this article.

\section{References}

1. Gallie WE, Thomson S. Volkmann's ischaemic contracture: two case reports with identical late sequelae. Can J Surg. 1960;3:164-66.

2. Janzen DL, Connell DG, Vaisler BJ. Calcific myonecrosis of the calf manifesting as an enlarging soft-tissue mass: imaging features. AJR Am J Roentgenol. 1993;160(5):107274.

3. O'Keefe RJ, O'Connell JX, Temple HT, Scully SP, Kattapuram SV, Springfield DS, et al. Calcific myonecrosis. A late sequela to compartment syndrome of the leg. Clin Orthop Relat Res. 1995;318:205-13.

4. Wang JW, Chen WJ. Calcific myonecrosis of the leg: a case report and review of the literature. Clin Orthop Relat Res. 2001;389:185-90.

5. Holobinko JN, Damron TA, Scerpella PR, Hojnowski L. Calcific myonecrosis: keys to early recognition. Skeletal Radiol. 2003;32(1):35-40.

6. Portabella F, Narvaez JA, Llatjos R, Cabo J, Maireles M, Serrano C, et al. [Calcific myonecrosis of the leg]. Rev Esp Cir Ortop Traumatol. 2012;56(1):46-50. 
7. Evers LH, Bartscher T, Lange T, Mailander P. Adder bite: an uncommon cause of compartment syndrome in northern hemisphere. Scand J Trauma Resusc Emerg Med. 2010;18:50.

8. Reading CJ. Incidence, pathology, and treatment of adder (Vipera berus L.) bites in man. J Accid Emerg Med. 1996;13(5):346-51.

9. Cawrse NH, Inglefield CJ, Hayes C, Palmer JH. A snake in the clinical grass: late compartment syndrome in a child bitten by an adder. Brit J Plast Surg. 2002;55(5):43435.

10. Tucker SC, Josty I. Compartment syndrome in the hand following an adder bite. J Hand Surg Br. 2005;30(4):434-35.

11. Karlson-Stiber C, Salmonson H, Persson H. A nationwide study of Vipera berus bites during one year-epidemiology and morbidity of 231 cases. Clin Toxicol. 2006;44(1):25-30.

12. Anz AW, Schweppe M, Halvorson J, Bushnell B, Sternberg M, Andrew Koman L. Management of venomous snakebite injury to the extremities. J Am Acad Orthop Surg. 2010;18(12):749-59.

13. Hamdi MF, Baccari S, Daghfous M, Tarhouni L. Upper limb compartment syndrome after an adder bite: a case report. Chin J Traumatol. 2010;13(2):117-19.

14. Dhar D. Compartment syndrome following snake bite. Oman Med J. 2015.

15. Wood D, Sartorius B, Hift R. Ultrasound findings in 42 patients with cytotoxic tissue damage following bites by South African snakes. Emerg Med J. 2016

16. Gopalakrishnakone P, Faiz M, Fernando R, Gnanathasan C, Habib A, Yang C, editors. Clinical Toxicology in Asia Pacific and Africa. Netherlands: Springer Netherlands; 2015.

17. Braud S, Bon C, Wisner A. Snake venom proteins acting on hemostasis. Biochimie. 2000;82(9-10):851-9.
18. Yuenyongviwat V, Laohawiriyakamol T, Suwanno P, Kanjanapradit K, Tanutit P. Calcific myonecrosis following snake bite: a case report and review of the literature. J Med Case Rep. 2014;8:193.

19. Chun YS, Shim HS. Calcific myonecrosis of the antetibial area. Clin Orthop Surg. 2010;2:191-94.

20. Blaylock R. Epidemiology of snakebite in Eshowe, KwaZulu-Natal, South Africa. Toxicon. 2004;43(2):159-66.

21. Kincaid R, Ruppert S. Rattlesnake envenomation and compartment syndrome: A case study. J Adv Nurs. 2009;11(1):1-7.

22. Leach RE, Hammond G, Stryker WS. Anterior tibial compartment syndrome. Acute and chronic. J Bone Joint Surg [Am]. 1967;49(3):451-62.

23. Wood D, Webb C, DeMeyer J. Severe snakebites in northern KwaZulu-Natal: treatment modalities and outcomes. S Afr Med J. 2009;99(11):814-18.

24. Malisano LP, Hunter GA. Liquefaction and calcification of a chronic compartment syndrome of the lower limb. J Orthop Trauma. 1992;6(2):245-47.

25. Early JS, Ricketts DS, Hansen ST. Treatment of compartmental liquefaction as a late sequelae of a lower limb compartment syndrome. J Orthop Trauma. 1994;8(5):445-48.

26. Tuncay IC, Demirors $\mathrm{H}$, Isiklar $\mathrm{ZU}$, Agildere $\mathrm{M}$, Demirhan B, Tandogan RN. Calcific myonecrosis. Int Orthop. 1999;23(1):68-70.

27. O'Dwyer HM, Al-Nakshabandi NA, Al-Muzahmi K, Ryan A, O'Connell JX, Munk PL. Calcific myonecrosis: keys to recognition and management. AJR Am J Roentgenol. 2006;187(1):W67-76.

This article is also available online on the SAOA website (www.saoa.org.za) and the SciELO website (www.scielo.org.za). Follow the directions on the Contents page of this journal to access it. 